\title{
Research on the Work of Letters and Visits in Colleges and Universities
}

\author{
Xiao Zhang \\ Office of Letters and Visits Supervision, Nanjing University of Finance \& Economics, Nanjing, Jiangsu, China
}

\begin{abstract}
Based on the domestic representative research of the complaint reporting handling office in common colleges and universities, this study analyzes the present situation of the petition work. At the same time, combined with our own work practice and thinking, the article believes that to do a good job of a complaint reporting in colleges and universities, we need to work from four aspects, including letters team construction, the mechanism improvement, the standard work procedures, and the network consciousness enhancement, constantly enhance the level of letters and visits office informatization, people-oriented, and pay attention to work methods.
\end{abstract}

Key words: colleges and universities; petition work; thinking

\section{Introduction}

In recent years, with the development of higher education and the deepening of various reforms in colleges and universities, the higher education system has formed many hot spots of petition. I have carried on the investigation to the present situation of the petition work in some colleges and universities in China and some beneficial thinking on how to do a good job combined with the practice of the petition work. Now I would like to summarize it for the readers.

\section{Introduction to the Petition Work of Representative Universities in China}

2.1 Peking University: legalization of petition work

(1) Manage schools according to law to protect the legitimate rights and interests of complainants. In September 2014, the University completed the formulation of the Constitution of Peking University (hereinafter referred to as the Constitution). The Constitution clearly states: "A legitimacy review must be conducted before any major decision is made. Decisions with general binding force that are made with respect to non-specific subjects shall be made in normative documents." At the same time, it also stipulates the division of labor between the Party and government, the division of academic power and administrative power, the protection mechanism of the rights of teachers and students, and the audit and supervision of the implementation of rules and regulations, and makes it clear that "abiding by the rules and regulations of the university, and other obligations agreed by laws, regulations and contracts" are the obligations that the faculty and staff should fulfill. At the same time, it constantly emphasized the "vigorous implementation" of the Articles of Association and various rules and regulations.

(2) Improve the mechanism of resolving conflicts and disputed in accordance with the law and regulations, and implement the system of the level-by-level termination of complaint reporting and the legal and litigation-related termination of complaint reporting in accordance with law. In 2013, Innovation Opinions of the General Office of the

Copyright (C) 2021 by author(s) and Frontier Scientific Research Publishing Inc.

This work is licensed under the Creative Commons Attribution International License (CC BY 4.0).

http://creativecommons.org/licenses/by/4.0/ 

Letters and Visits and Emphasizing the Work Style of the Masses revised regulations of the School of Letters and Visits, Beijing university, to further improve the complaint mechanism, clear the competent authorities responsible for the complaint, and set up a petition working group and a petition office to coordinate the overall petition work of the university. We will carry out a system of joint meetings on complaint reporting to study and consult on major, complex and difficult complaint reporting matters. At the same time, the new revision of the regulations further clarify that the complaint should adhere to the combination of "grassroots director should be responsible" and "the combination of solving problems in accordance with the law, timely and locally and counseling education". Adhere to the principle of complaint involving lawsuit mechanism, put forward the overall requirement for reform according to visits, strictly implement litigation and separation of the handling of complaint reporting, and implement the law-related complaint involving lawsuit end system in accordance with the law. This establishes a mechanism for resolving conflicts and disputes according to law in the form of the Basic Law for complaint reporting work, so as to ensure that relevant work operates within the orbit of the rule of law and the scope of rules and regulations, and ensure that reasonable and legitimate appeals can be obtained in accordance with regulations and procedures. In practical work, the office of letters and visits of the university and other related units ensure that each link is in strict accordance with the relevant regulations in substance and procedure from the first reception and registration of letters and visits to the sub-handling, reporting and coordination of letters and visits, until the reply to the complainants.

\subsection{Tsinghua University: scientific petition work}

(1) Improve the organizational system, realize multi-department linkage, and promote social management innovation. The university has formed a "three-level linkage" working mode with the general responsibility of the Party secretary, the general lead of the executive vice president, and the general coordination of the Party committee office and the president's office. First, the general dispatching of the two offices. The Party school runs a petition office. Second, departments builds a team to realize the petition center down. Third, the central assistance of the department. Through the establishment and improvement of the work mechanism of letters and visits, the overall resultant force for handling letters and visits has been initially formed.

(2) We should improve the management system, enhance the execution of complaint reporting work, and strengthen the professionalization and standardization of complaint reporting work. First, improve the registration system. Number and register letters from the superior and the masses, and submit them to the relevant leaders for approval. Second, adhere to the review system. Letters and visits shall follow the procedure of "receiving visits from leaders for review -transferring to the handling department -- reply", and shall be dealt with centrally according to leaders' instructions and management authority. Third, strengthen oversight mechanisms. Through the supervision and handling of the complaint and visiting matters, the solution of the complaint and visiting problems is promoted and the effectiveness of the supervision is improved. Fourth, establish a feedback mechanism. For complaint reporting handled directly, all departments shall, in strict accordance with the relevant provisions on the time limit for handling, timely feed back the results of handling to the objects of complaint reporting. Fifth, implement the target assessment system. The work of letters and visits shall be included in the assessment of the work of all departments and their principals, and shall be signed level by level.

(3) Actively contact the masses and take the initiative to receive visits. The school adheres to the system of reception day for school leaders. Once a month, a school leader takes the lead and collects the opinions and requirements of the masses face to face with the heads of relevant departments, taking the initiative to solve universal and tendentious 
problems. Before each reception day, the time and place of the reception day should be announced in advance, and the student system will actively collect more questions and suggestions from students.

(4) Do research, timely report problems and change passive to active. Over the years, the school has been adhering to the information reporting system, timely summarizing the information of letters and visits to report to the school, and predicting unstable factors in advance. At the weekly group meeting held by the leaders in charge of the report on the work of letters and visits, study and deal with opinions, deployment of work in advance. For the hot and difficult issues reflected by teachers, students and staff, a special research report is seriously summarized and formed, to provide a powerful reference for the leaders to make scientific decisions and timely improve the work of the department.

2.3 Nanjing University: constructing the pattern of large-scale petition work

(1) All departments participate together to promote management through letters and visits. The university has set up a leading group for letters and visits with the deputy secretary of the Party committee directly in charge of the work. The leading group has an office in the Party committee office, which is responsible for coordinating and handling the daily work of letters and visits in colleges and universities, adhere to the school leaders reception day system, arrange and announce a school leaders to receive teachers and students in advance every week. On the basis of the first-level letters and visits institution in the school, a second-level letters and visits work institution is set up, which is jointly managed by the school and all units, striving to build a large pattern of letters and visits work with the coordination of the Party and the office, the participation of departments, each taking his own responsibility and the formation of joint forces. The Party committee office uniformly accepts letters and visits, transfers general matters to the central departments for handling and tracking supervision, and carries out supervision and handling of comprehensive and important matters after the relevant leaders sign and approve the opinions and give the instructions of the leaders in charge.

(2) Online and offline should be combined to actively respond to online petition work. The university has always attached great importance to understanding the social situation and public opinion through the Internet, especially paying attention to the issues that affect the stability and development of the university and have a significant impact on the emotions of the staff. The school took the lead in opening the "president's mailbox" on the campus BBS, which has now evolved into the "school office mailbox" including the mailboxes of 18 functional departments. The president's office is responsible for the daily affairs management of the president's mailbox, and the relevant functional departments are responsible for the "top leader" of the school's mailbox, and each of them will assign a staff member to be responsible for the immediate view and reply of the page.

2.4 South China Agricultural University: standardization of petition work

(1) Smooth channels for handling complaints and visits. Set up the president's mailbox and a monthly reception day for school leaders. The administrative department of the school office has appointed a special person in charge of letters and visits, and set up a telephone complaint registration system. These practices are similar to colleges and universities, no longer detailed.

(2) Improve the mechanism for handling letters and visits. In the process of handling letters and visits, the school mainly focuses on the work norms of reception, recording, registration, coordination, planning, approval, reading, supervision, and result processing. In the reception of visitors, establish the "Four Ones" work standard, namely "one greeting, one smiling face, one chair, and one cup of hot tea". In the recording and registration link, the establishment of the "one table" work standard, that is, all forms of letters and visits to the "letter and visit processing table", unified registration, numbering, processing. in the coordination, planning, approval, review, supervision links, the establishment of all levels of the "head" with overall responsibility work norms. 
(3) In the result processing link, the establishment of "must answer, choose to answer" work norms. For the petitioners who sign their letters and leave their telephone numbers, the standard of work is "must answer", informing the results in corresponding ways and collect their opinions. For anonymous letters and visits, the standard of work is "choose to answer", that is, to choose those universal, hot issues of public concern, public answers in the school newspaper.

\section{Analysis of the Work of Letters and Visits in Colleges and Universities}

3.1 Analysis of the present situation of petition work in colleges and universities

At present, the petition work in colleges and universities has formed a lot of hot issues, which are numerous and complicated. There are two main causes of these hot issues. First of all, colleges and universities have many levels of management, which makes it difficult to manage. School management involves the management of teaching and scientific research, the management of teachers, the logistics management of teachers and students' study and life, etc. The large number of people increases the difficulty of management work. It is found from the survey that there are various problems in the petition channel of colleges and universities, such as salary and treatment, which reflect the vital interests of faculty and staff, the management of student status, enrollment and graduation distribution, teaching, and the conduct of the Party and clean government. In addition to the Party and school office equipped with the letter and visit departments to deal with the school's letter and visit matters, each department also has corresponding personnel to help deal with the letter and visit problems. However, due to the large number of faculty, staff and students, and the many lines of management, the problems involved are also many, so there are many contradictions accordingly. Secondly, many reform measures involve the vital interests of teachers and students. In recent years, reform measures involving colleges and universities have been carried out one after another with great strength and more faculty and staff involved. Besides, college students are young, with high knowledge level, active thoughts and strong consciousness of safeguarding rights. Therefore, many problems can be directly reflected through letters and visits. For example, in the process of the reform of the university logistics system, there are problems including service attitude, the relationship between cadres and the masses, canteen health and price, the management of student dormitories and teaching buildings, campus environment remediation, and campus communication network construction. In the reform of the personnel system, there are the ideological problems in the process of waiting for and transferring the teaching staff, the placement of the unemployed staff after the divestment of the school property, the contradictions and disputes after the separation of income and treatment levels, the problems of personnel simplification and reasonable diversion, etc. All of these have become the hot issues of letters and visits in universities in recent years.

\subsection{The system construction of petition work in colleges and universities at present}

From the analysis of the investigation, the Party and government leaders in these universities pay more attention to the petition work. For example, most colleges and universities have established the "mass visit and reception day system" of school leaders, set up the leading group of school letter and visit work and the letter and visit contact mailbox, and adopted the regular meeting system of letter and visit work, the reply system, the supervision system, the secretary's home visit system, the leader-in-charge system, the leaders contact grass-roots system and other measures. On the one hand, these measures enable the leading cadres of the Party and government in colleges and universities to directly listen to the aspirations of the masses, approach the faculty and students, and provide the opportunity for the faculty and staff to have a direct dialogue with the leaders. On the other hand, the organization also guarantees the leadership of the petition work and improves the efficiency of handling the petition matters.

\section{Reflections on the Work of Letters and Visits in Colleges and Universities}

The work of letters and visits is an important set of mechanisms to resolve conflicts and problems. Based on the 
investigation and thinking, and according to the characteristics of the petition work in colleges and universities, the following thoughts are given for the future petition work.

\subsection{Strengthening the work force for handling letters and visits}

When dealing with problems, we should not only emphasize policies and principles, but also calmly and flexibly deal with them. We should both carry out in-depth investigation and do a good job of multi-Party coordination. This requires the staff not only to have excellent political consciousness, good overall awareness, legal awareness, responsibility awareness and service awareness, but also to have a higher theoretical literacy and professional level, to adapt to this requirement must pay attention to and strengthen the study. First of all, we should study and deeply understand the Party's line, principles and policies, comprehensively grasp and correctly use the national Regulations on Letters and Visits, Regulations on Education Letters and Visits, relevant documents of Jiangsu Provincial Government Letters and Visits Bureau, and familiarize myself with the various internal rules and regulations of the unit. Secondly, we should strengthen the study of comprehensive knowledge. It is necessary to learn and master certain knowledge of sociology, psychology and management, to understand the general knowledge of each major in the school, and to have strong language expression ability, organization and coordination ability, and the ability to distinguish right from wrong.

\subsection{Improving mechanisms and standardizing working procedures}

In accordance with the principle of "taking responsibility at different levels and handling it at the same time", we will establish and improve complaint reporting offices at all levels and improve the second-level complaint reporting work network. For example, the Department of Supervision and Letters and Visits is specifically responsible for the organization, coordination and guidance of letters and visits, as well as the reception and processing of daily letters and visits. Each school, department, office and other secondary units have a special person in charge of letter reporting work, or set up parttime letter petitioners, responsible for the implementation, handling, supervision and feedback of letter reporting matters assigned or transferred at all levels, understanding the ideological dynamics, problems and difficulties of teachers and students, and grasping the implementation of various policies of the school at the grassroots level. And the relevant information will be timely and accurately reflected to the school leaders or supervision and letters and visits section, for making decisions and solving key, difficult problems to provide reliable basis.

Through the establishment of rules and regulations, we will promote the scientific, standardized and institutionalized handling of complaint reporting. Establish and improve the responsibility system for complaint reporting work, which can clarify the division of labor, assign responsibility to people, straightening out relations and standardize procedures, so as to ensure that questions between teachers and students are listened to, asked and taken care of. Adhere to the leaders reception day system and leaders appointment system, which can promote the communication between the school leaders and teachers and staff, close the relationship between cadres and the masses, which is conducive to resolve all kinds of contradictions and solve the actual difficulties and problems of the masses. The establishment of the supervision and handling system of complaint and visiting cases can promote the solution and implementation of the complaint and visiting problems, improve the efficiency and effect of the handling of complaint and visiting matters, and promote the healthy development of the complaint and visiting work in colleges and universities. In addition, we should establish and improve the regular meeting system, major event reporting system, joint receiving system, target management assessment system, notification system, two-level management system, termination system, registration, handling and reply system of letters and visits.

The work of complaint reporting is legalized and follows the principle of "performing statutory duties and not doing anything without legal authorization". The handling of complaint reporting is based on a strong policy and law. On the one 
hand, we should combine the petition work with the administration of the school according to law, consciously bring the policies, rules and regulations of the school into the legal framework, so as to make them conform to the legal norms and be implemented according to law. In this way, it can not only protect the interests of the school, but also take the initiative to safeguard and protect the legitimate rights and interests of the majority of teachers and staff. On the other hand, further publicity and guidance of the majority of faculty and staff, especially students, to study, understand, believe, use, and abide by the lawing, to exercise their rights according to the policy and legal provisions, and to change the concept that some teachers and students "trusting pension not law". Of course, those who disturb the petition order should also adhere to the principle and act in accordance with the law.

4.3 Strengthen the network consciousness and constantly improve the level of information office letters and visits

The Internet has become a part of the daily life of the majority of teachers and students. The school forum, public account, QQ group, WeChat group, and class micro came into being. Here, teachers and students can speak freely and express their demands. Therefore, the use of the network can collect teachers and students' real ideas and practical difficulties and master more accurate and extensive information. According to the information, the school can deal with and give feedback in time to resolve the conflicts in the bud, so as to maintain the stability and promote the development of the school.

4.4 People oriented and pay attention to working methods

Petition work is a kind of mass work which involves a wide range and complex contents. No matter what the identity of the visitor is or what problems he or she reflects, the complaint reporting staff should proceed from the overall situation and reality, warmly receive and flexibly respond to the situation according to relevant policies and procedures, so as to "greet the visitor with a sound when coming, send a sound when walking, respond with a sound when asking and respond with an echo when handling".

(1) Be honest with each other and keep good records

Teachers and students sometimes inevitably have some negative emotions in the process of interview, mostly due to difficulties in the work, life, learning process. In this case, we can not be influenced by petitioners emotion, and intensify the conflict. Instead, we should sincerely remove worries and difficulties for the visitors, alleviate the contradiction of breakthrough, listen patiently to visitors, carefully ask and record the relevant situation, so as to create a good atmosphere for the next step to resolve disputes and contradiction.

(2) Stick to principles and convince others with reason

Following the principle of "meeting reasonable demands, refusing unreasonable demands, and achieving win-win demands", and actively coordinating with relevant departments to solve reasonable, legal and permissible demands as soon as possible in accordance with relevant policies. For the problems that cannot be solved temporarily due to the limitation of the conditions, the situation should be explained in time, and the explanation work should be done patiently and carefully to obtain the understanding and support of teachers, students and staff. For unreasonable request, do not accommodate, do not evade, hard and soft help, and do a good job of persuasion education.

(3) Strengthen coordination and multi-party cooperation.

The handling of complaint reporting matters often requires joint consultation and close cooperation between several departments, so it is necessary to effectively do a good job in communication, organization and coordination. In addition, it is also necessary to follow up and supervise the handling of complaint reporting cases transferred to centralized administrative departments to ensure timely handling of complaint reporting issues. 
(4) Timely feedback and do a good summary

The handling opinions and results of complaint reporting should be reported and fed back in time, and major problems should be followed up afterwards. We should timely analysis and summary of the petition work and grasp the rules, in order to serve the development of the future work.

\section{Conclusions}

In short, letters and visits provide a way for teachers, students and staff to express their feelings and solve problems. It is an important way for the school to communicate and understand the school situation, and an important channel for the school to find and solve problems in the process of development. Therefore, the staff of the letter and visit room should work hard to do a good job of letter and visit with the spirit of masters, and strive to serve the teachers and students of the whole school.

\section{Conflicts of Interest}

The author declares no conflicts of interest regarding the publication of this paper.

\section{References}

[1] Ma Z.J. (2020). Research on Situation Analysis and Countermeasures of Petition Work in Colleges and Universities in the New Era. Jilin Education, (11): 67-69.

[2] Huang B.K. (2011). Research on Characteristics and Countermeasures of Petition Work in Colleges and Universities under the New Situation. Journal of Lanzhou Institute of Education, 27(03): 95-96.

[3] China Legal Publishing House. (2020). Petition regulations annotation and supporting. China Legal Publishing House, Beijing. 